\title{
Removal of laryngeal mask airway: awake vs anesthetized
}

\author{
Jong-Man Kang \\ Department of Anesthesiology and Pain Medicine, Kyung Hee University, East-West Neo Medical Center, Seoul, Korea
}

Anesthesiologists have been debating on the timing of tracheal extubation (removal of laryngeal mask airway, laryngeal tube, etc.) in children on whether the extubation has to be done while the children are anesthetized or awake. Some studies have shown that removal of airway devices in an anesthetized state was accompanied by less minor respiratory complications such as coughing, hypersalivation and desaturation than in awake [1]. However, the upper airway obstruction after the removal of airway devices in the anesthetized state remains as a potential life-threatening risk.

Kim et al. [2] suggest in this month's edition that the use of caudal block may be a solution in lowering both minor and major complications. The laryngeal mask airway was designed originally to be placed within the mouth until the return of protective airway reflexes. However, in clinical practice, it is true that many anesthesiologists have not always followed this rule [1].

Caudal block is one of the most frequently used regional blocks in pediatric patients. This technique provides postoperative analgesia after infraumbilical operations as an adjunct to general anesthesia. Neuraxial anesthesia has been reported to have direct sedative properties and to markedly reduce the amount of hypnotic agents required for general anesthesia. The assumptive mechanism includes decrease in the general anesthetic demand by blocking the pain from surgical site and suppressing movement in response to a noxious stimulus [3].

Kim et al. [2] have also shown that the apparently separate two anesthetic procedures- removal of laryngeal mask airway and caudal block, could be clinically associated. However, there are several points to be taken into consideration. Firstly, it seems somewhat unethical to observe that there is significant difference in managing the postoperative pain between the two groups, considering that there was nothing done in the control group comparable to the caudal block. Secondly, since they have already showed that laryngeal mask airway removal could be accomplished without coughing, moving, or any other airway complication at $\mathbf{1 . 8 \%}$ end-tidal sevoflurane concentration in $50 \%$ of anesthetized children in their previous article, the need for control group appears questionable [4]. Thirdly, this paper is deficient in delineating the level of the caudal analgesia that is truly blocked in the children. Despite the existing difficulties of checking the truly blocked level, it could have been checked right after the extubation. In addition, use of various concentrations or volume of the local anesthetics for caudal blocks may have strengthened the author's opinions. Finally, there is a need to conduct such studies by recruiting a number of patients as it could bring in a drastic understanding and methodological changes in anesthesiologists.

To be conservative or not, that is not only Hamlet's soliloquy. It is difficult for clinicians to change their concepts, traditions and practices based on a single published literature. The efforts of Kim et al. [2] have helped us by providing a new strategy in an effort to increase safety in removing the laryngeal mask airway.

\section{References}

1. Kitching AJ, Walpole AR, Blogg CE. Removal of the laryngeal mask airway in children: anaesthetized compared with awake. Br J Anaesth 1996; 76: 874-6.

2. Kim JS, Park WK, Lee MH, Hwang KH, Kim HS, Lee JR. Caudal analgesia reduces the sevoflurane requirement for LMA removal in anesthetized children. Korean J Anesthesiol 2010; 58: 527-31.

3. Xiao WJ, Deng XM, Tang GZ, Lu MP, Xu KL. Caudal anesthesia reduces the minimum alveolar concentration of enflurane for laryngeal mask airway removal in boys. Can J Anaesth 2002; 49: 194-7.

4. Lee JR, Kim SD, Kim CS, Yoon TG, Kim HS. Minimum alveolar concentration of sevoflurane for laryngeal mask airway removal in anesthetized children. Anesth Analg 2007; 104: 528-31.

Corresponding author: Jong-Man Kang, M.D., Department of Anesthesiology and Pain Medicine, Kyung Hee University, East-West Neo Medical Center, 149, Sangil-dong, Gangdong-gu, Seoul 134-090, Korea. Tel: 82-2-440-6193, Fax: 82-2-440-7808, E-mail: kjm@khnmc.or.kr (c) This is an open-access article distributed under the terms of the Creative Commons Attribution Non-Commercial License (http:// creativecommons.org/licenses/by-nc/3.0/), which permits unrestricted non-commercial use, distribution, and reproduction in any medium, provided the original work is properly cited. 